Neuroepidemiology 2013;40:295

DOI: $\underline{10.1159 / 000346274}$

\title{
Guillain-Barré Syndrome after H1N1 Influenza: A Concern
}

Viroj Wiwanitkit

Hainan Medical University, Haikou, China; Faculty of Medicine, University of Nis, Nis, Serbia; Joseph Ayo Babalola University, Ikeji-Arakeji, Nigeria

The report on Guillain-Barré syndrome (GBS) following H1N1 influenza vaccination is very interesting. Souayah et al. [1] concluded that 'some GBS cases may be triggered by $\mathrm{H} 1 \mathrm{~N} 1$ vaccination' and proposed 'early recognition, treatment, and active surveillance in the post-vaccination setting'. Indeed, GBS is usually a concern as an adverse effect of vaccination. The seriousness of this GBS is confirmed and it is a consideration in the implementation of any vaccination. It is important to compare risk and benefit in any vaccination [2]. Based on the author's previous report, it is confirmed that the benefit of vaccination is greater than the risk [2]. Indeed, Souayah et al. [3] also accepted and reported this fact in their parallel publication.

\section{References}

1 Souayah N, Yacoub HA, Khan HM, Michas-Martin PA, Menkes DL, Maybodi L, Qureshi AI: Guillain-Barré syndrome after H1N1 vaccination in the United States: a report using the CDC/FDA Vaccine Adverse Event Reporting System (2009). Neuroepidemiology 2012;38:227-232.

2 Wiwanitkit V: Pandemic influenza A: H1N1 2009 vaccine: a concern on neurological adverse effect. Indian J Community Med 2012;37:203-204.

3 Souayah N, Yacoub HA, Khan HM, Farhad K, Mehyar LS, Maybodi L, Menkes DL, Qureshi AI: Guillain-Barré syndrome after influenza vaccination in the United States: a report from the CDC/FDA Vaccine Adverse Event Reporting System (1990-2009). J Clin Neuromuscul Dis 2012;14:66-71.

\section{KARGER}

(C) 2013 S. Karger AG, Basel

0251-5350/13/0404-0295\$38.00/0 